Titulo do Trabalho

\title{
RESPONSABILIDADE SOCIAL E SUSTENTABILIDADE NA INDÚSTRIA EXTRATIVISTA DO PARÁ: O CASO DA BAUXITA EM JURUTI
}

Nome do Autor (a) Principal

Flávia Maria de Mattos Donadelli

Nome (s) do Co-autor (a) (s)

\section{João Paulo Cândia Veiga; Rodrigo Brandão}

Instituição ou Empresa

Instituto de Relações Internacionais - Universidade de São Paulo (IRI-USP)

Instituição (s) de Fomento

Instituto de Relações Internacionais - Universidade de São Paulo (IRI-USP)

E-mail de contato

donadelliflaviamaria@hotmail.com

RESUMO: O presente trabalho procurou apresentar e avaliar a efetividade de um arranjo institucional (Conselho Juruti de Sustentabilidade - ConJuS) tripartite (sociedade civil, empresas e prefeitura) cujo objetivo é a promoção do desenvolvimento local sustentável, criado em decorrência da instalação (e conseqüentes impactos socio-ambientais) de uma multinacional norte-americana (ALCOA) para a exploração de um recurso natural não renovável - a bauxita. A operação acontece em uma comunidade tradicional do interior no extremo oeste do Pará, em uma cidade chamada Juruti, próximo à fronteira com o Estado do Amazonas. De forma inovadora, a empresa definiu um tripé de sustentabilidade através de indicadores produzidos pela FGV (Fundação Getúlio Vargas), pelo financiamento de projetos de desenvolvimento local (Funbio), e pela criação, em parceria com a comunidade local, de um arranjo institucional denominado Conselho Juruti Sustentável (ConJuS) para organizar, debater e canalizar demandas voltadas à 
sustentabilidade do projeto de mineração. Assim, com a intenção de analisar os resultados efetivos desse modelo inovador de gestão sócio-ambiental da indústria extrativista, prioritariamente do ConJuS, desenvolveu-se, na primeira metade de 2010, uma pesquisa de campo na região com importantes resultados acerca da potencialidade e limitações desse tipo de iniciativa.

Palavras-chave: Indústria Extrativista, Sustentabilidade, Comunidades Locais

\section{1) INTRODUÇÃO}

A indústria extrativista, tradicionalmente, sempre esteve cercada por graves incidentes sócio-ambientais e conturbadas relações comunitárias em termos trabalhistas e ambientais. A comoção pública causada por desastres como, por exemplo, o imenso derramamento de petróleo da Exxon Valdez na costa do Alasca em 1989; a morte do ativista de direitos humanos Ken Saro-Wiwa em protestos contra a Shell da Nigéria em 1993 ou as gravíssimas implicações do financiamento da indústria de diamantes à guerra civil da Serra Leoa em 1991, fizeram, no entanto, com que as exigências sociais em relação à transparência, responsabilidade sócio-ambiental e prestação de contas do setor aumentassem muito.

Entre os diferentes "modelos" já testados por esse setor produtivo, os temas da relação empresa-comunidades, os direitos de comunidades originárias (indígenas, quilombolas), as políticas públicas voltadas para o assentamento de grupos sociais impactados e a relação entre a empresa a o ciclo da política local, todos esses elementos relevantes da dimensão propriamente 'social' do tripé de sustentabilidade ${ }^{1}$, foram sempre relegados ou mal considerados tanto pelas empresas extrativistas quanto pela literatura especializada. Na medida em que a globalização uniformiza princípios, critérios e indicadores de CSR (Corporate Social Responsibility), entretanto, que passam a ser objeto de consideração das grandes empresas, e que a pressão da opinião pública

\footnotetext{
${ }^{1}$ O conceito de sustentabilidade de acordo com sua versão decorrente do Relatório Brudtland de 1992 envolve o tripé de garantir o crescimento econômico, promover o desenvolvimento social, e garantir, ao mesmo tempo, a conservação ambiental.
} 
mundial estabelece demandas mais rigorosas, novas experiências como a proposta da Alcoa em Juruti-PA, podem ser um 'campo de prova' de novas e fecundas abordagens acerca de como considerar a dimensão sócio-ambiental local de grandes empreendimentos extrativistas.

Após a constatação dos graves efeitos de antigos modelos de interação entre empresas e comunidades locais, como por exemplo o modelo "Company-Town", implantado pela Ford no Pará em 1928 com a criação de uma cidade exclusiva para seus funcionários (a Fordlândia) com padrões de vida completamente diversos daqueles da população local ou ainda as experiências paternalistas de provisão de bens públicos em um modelo de filantropia sem qualquer diálogo direto com a sociedade, a Alcoa se propôs a implantar um novo modelo baseado em um tripé que visa garantir a sustentabilidade da região. Esse tripé baseia-se assim em indicadores sócio-ambientais produzidos pela FGV (Fundação Getúlio Vargas), pelo financiamento de projetos de desenvolvimento local por um fundo específico gerido pelo Funbio (Fundo Brasileiro para a Biodiversidade), e pela criação, em parceria com a comunidade local, de um arranjo institucional de diálogo e canalização de demandas denominado Conselho Juruti Sustentável (ConJuS). ${ }^{2}$

O ConJuS, foco central adotado pela pesquisa, apesar de possuir um estatuto oficial, ainda está em processo de construção e de aprimoramento por meio de um diálogo constante entre o setor privado, o governo local e a sociedade civil de Juruti. Ao término desse processo de consolidação, a empresa afirma esperar que o ConJus seja um fórum público independente capaz de identificar e de solucionar os problemas sócioeconômicos do município de maneira auto-sustentável. Nossa análise revelou, no entanto, diversos desafios que ainda terão que ser enfrentados para que tal objetivo possa, de fato, ser atingido.

\section{2) OBJETIVO GERAL}

O objetivo geral da pesquisa foi o de acessar, de maneira independente e imparcial, as potencialidades e limitações do novo modelo de gestão dos impactos sócio-

\footnotetext{
2 Juruti Sustentável, uma proposta de modelo para o desenvolvimento local. GVCes, 2008 Disponível em:
} http://www.alcoa.com/brazil/pt/juruti_info_page/Juruti_port.pdf Acesso em: Julho, 2010. 
ambientais locais decorrentes da implantação de uma mina de extração de bauxita em uma pequena comunidade da região oeste do Pará pela multinacional norte-americana Alcoa.

\section{3) OBJETIVOS ESPECÍFICOS}

O objetivo específico da pesquisa foi o de avaliar os impactos, potencialidades e limitações da implantação do ConJuS (Conselho Juruti de Sustentabilidade) para o desenvolvimento de relações mais equilibradas entre a comunidade de Juruti e a empresa Alcoa. Essa análise, portanto, buscou acessar a contribuição desse mecanismo institucional para a promoção de um ciclo de desenvolvimento sólido e sustentável durante e após o período de extração da bauxita na região.

\section{4) METODOLOGIA}

A pesquisa, decorrente de uma parceria entre a Universidade de São Paulo (USP) e a Columbia University's School of International and Public Affairs (Columbia - SIPA) nos Estados Unidos, foi conduzida em três etapas distintas. A primeira, teórica, consistiu em uma revisão da literatura a respeito de responsabilidade social corporativa, modelos de condução sócio-ambiental de empreendimentos de mineração ao redor do mundo e uma análise específica dos documentos relativos ao caso e contexto da instalação da Alcoa em Juruti-PA.

A segunda, que se dividiu em duas partes, consistiu em um trabalho de campo com a realização de duas visitas do grupo de pesquisadores da USP e da Columbia à Juruti-PA, com entrevistas aos membros do ConJuS de todos os setores (sociedade civil, setor privado e setor público), participação em reuniões do Conselho, visitas à mina e à comunidades, como é o caso de Juruti Velho, que optaram por não fazer parte do ConJuS. Procurou-se nesse momento, ouvir e documentar versões e depoimentos os mais diversos possíveis, para que se pudesse realizar uma análise imparcial e equilibrada do ConJus. 
A terceira etapa da pesquisa consistiu na revisão do material de campo coletado bem como na realização de amplos debates e troca de impressões entre os pesquisadores e culminou na redação de um relatório final o Alcoa's Brazil new Sustainability Modelo for Mining: an independent Review, concluído em maio de 2010.

\section{6) RESULTADOS}

A análise realizada revelou, assim, diversos constrangimentos que devem ser solucionados para um sólido estabelecimento do CONJUS em longo prazo. Alguns dos principais constrangimentos observados foram: expectativas divergentes entre os membros em relação aos objetivos do Conselho, pouca clareza quanto a alguns mecanismos internos de tomada de decisão e estabelecimento da agenda, dificuldades de monitoramento e avaliação de desempenho, além da falta de autonomia financeira.

Além disso, o aspecto tripartite do Conselho, caracterizado por envolver representantes do setor público, privado e organizações da sociedade civil tem se demonstrado incompleto pela pouca participação verificada de membros do setor público.

Outro desafio a ser enfrentado constitui-se no trade-off a respeito do nível adequado de interferência da ALCOA sobre o Conselho. Ao mesmo tempo em que a interferência excessiva pode minar a independência e credibilidade do Conselho perante os seus membros, um maior afastamento pode representar um aumento das dificuldades internas de coordenação e motivação dos membros.

Sendo assim, o desenvolvimento institucional do CONJUS está sujeito a diversos desafios que deverão que ser enfrentados para um efetivo desenvolvimento do CONJUS como uma instituição sólida e de longo prazo.

\section{7) CONSIDERAÇÕES FINAIS}

Assim com o intuito de analisar as potencialidades e limitações de um novo modelo de gestão sócio-ambiental da indústria extrativista proposto pela Alcoa para a sustentabilidade local da região de Juruti-PA, o presente trabalho focou suas atenções no 
contexto de funcionamento de um inovador mecanismo institucional de articulação e mobilização social em prol da sustentabilidade, o Conselho Juruti de Sustentabilidade (ConJuS).

Conforme observado, porém, apesar de muito promissora, a iniciativa carece ainda de diversos ajustes institucionais bem como de uma maior adaptação e convergência de expectativas e entendimentos entre seus membros. Tal evolução, além de um maior "empoderamento" da sociedade civil em relação à administração e condução do Conselho, envolve necessariamente uma compreensão mais generalizada e uma maior valorização da importância do mecanismo como fundamental a um desenvolvimento sólido e sustentável da região a longo prazo.

\section{REFERÊNCIAS}

ABDALA, Fábio (2009) "Juruti Sustentável: Uma Proposta de Modelo para Mineração e Desenvolvimento Local", artigo no formato "Trabalho Técnico", apresentado no 6 Congresso Brasileiro de Mineração, Belo Horizonte, agosto.

BEBBINGTON, Anthony J.; BURY, Jeffrey T. (2009) "Institutional Challenges for Mining and Sustainability in Peru", PNAS, Vol 106, n. 41, pp. 17296-17301.

DAGNINO, Evelina (Org.) (2002) Sociedade civil e espaços públicos no Brasil. São Paulo: Paz e Terra.

FRYNAS, Jedrzej George (2005) "The False Developmental Promise of Corporate Social Responsability: Evidence from Multinational Oil Companies", International Affairs, 81 (3), pp. 581-598.

FULMER, Amand M.; GODOY, Angelina S.; NEFF, Philip (2008) "Indigenous Rights, Resistence and the Law: Lessons from Guatemala Mine", University of Miami 50 (4), pp. 91-121.

GURZA LAVAlle, A. ; HOUtZAGeR, P. P. ; CASTELlO, G. (2006) Representação Política e Organizações Civis: Novas Instancias de Mediação e os Desafios da Legitimidade. Revista Brasileira de Ciências Sociais, v. 21, n. 60, p. 43-66. 
"Juruti Sustentável, uma proposta de modelo para o desenvolvimento local." GVCes, 2008.Disponível em: http://www.alcoa.com/brazil/pt/juruti_info_page/Juruti_port.pdf Acesso em: Julho, 2010.

NEWELL, Peter (2005) "Citizenship, Accountability and Community: The Limits of CSR Agenda" International Affairs 81 (3), pp. 541-557.

REES, Caroline (2009) Report of the International Roundtable on Conflict Management and Corporate Culture in the Mining Industry Harvard Kennedy School, Harvard, Cambridge, Massachusetts. 